\title{
O INHANDUVÁ (PROSOPIS AFFINIS SPRENG.) NO RIO GRANDE DO SUL. 7 - OCORRÊNCIA NATURAL NA PLANÍCIE DE INUNDAÇÃO DO ARROIO ITAPORORÓ, MUNICÍPIO DE ALEGRETE ${ }^{1}$
}

\author{
FABIANO DA SILVA ALVES ${ }^{2}$ JOSÉ NEWTON CARDOSO MARCHIORI $^{3}$
}

\section{RESUMO}

É descrito um parque natural de inhanduvá existente na planície de inundação do arroio Itapororó, no município de Alegrete (Rio Grande do Sul).

Palavras-chave: Prosopis affinis, Fitogeografia, Alegrete, Rio Grande do Sul.

\section{SUMMARY}

[Prosopis affinis Spreng. in Rio Grande do Sul state, Brazil. 7 - Natural occurrence on Itapororo stream's flood plain, municipality of Alegrete, Brazil].

A new occurrence of Prosopis affinis thicket is described in Rio Grande do Sul state (Brazil), growing on the flood plain of Itapororo stream, municipality of Alegrete.

Key words: Prosopis affinis, Phytogeography, municipality of Alegrete, Rio Grande do Sul state, Brazil.

\section{INTRODUÇÃO}

Com as recentes descrições dos parques de inhanduvá do Loreto (Marchiori et al., 2010), da várzea do rio Santa Maria (Alves \& Marchiori, 2011) e da várzea do Ibicuí, no município de Cacequi (Marchiori \& Alves, 2011), o largo vale deste rio passa a ser considerado como rota imigratória da referida espécie em direção ao centro do Rio Grande do Sul, por ser a única área de solos aluviais que atravessa o Planalto da Campanha, unindo o vale do rio Uruguai e as planícies da Mesopotâmia argentina, à província geomorfológica da Depressão Central, ambas marcadas por formações sedimentares.

Tais ocorrências, juntamente com o parque de inhanduvá do Jarau, associado a lente sedimentar no interior do Planalto da Campanha (Alves \& Marchiori, 2010), constituem disjunções notáveis e de caráter relitual, que ampliam, significativamente, a distribuição geográfica da espécie no Rio Grande do Sul. Des- te modo, não mais se sustentam, por equivocadas, as referências bibliográficas que limitavam a ocorrência natural do inhanduvá, no Estado gaúcho, à área do "Parque Estadual do Espinilho", em Barra do Quaraí, tese defendida por Galvani (2003) e Galvani \& Baptista (2003), ou à planície aluvial existente entre esta cidade e Uruguaiana, referida por Veloso \& Góes-Filho (1982).

Sobre este tema, aliás, cabe salientar que Marchiori et al. (1983, 1985A, 1985B) e Marchiori (2004) já comentavam sobre a presença do inhanduvá em "pontos isolados da Campanha do Sudoeste", "notadamente ao longo da bacia do rio Ibicuî”. Mesmo não sendo novidade, tais disjunções ainda estavam à espera de necessário registro na literatura fitogeográfica.

Ao descrever um quarto parque inhanduvá em área disjunta na bacia do Ibicuí, o presente artigo visa a contribuir para o conhecimento da distribuição geográfica da espécie no Rio Gran-

Recebido em 15-4-2011 e aceito para publicação em 10-5-2011.

2 Biólogo, MSc. Professor da Universidade da Região da Campanha (URCAMP - Alegrete). Doutorando do Programa de Pós-Graduação em Engenharia Florestal, UFSM.

3 Engenheiro Florestal, Dr. Professor Titular do Departamento de Ciências Florestais, UFSM. Bolsista de Produtividade em Pesquisa ( $\mathrm{CNPq}$ - Brasil). 


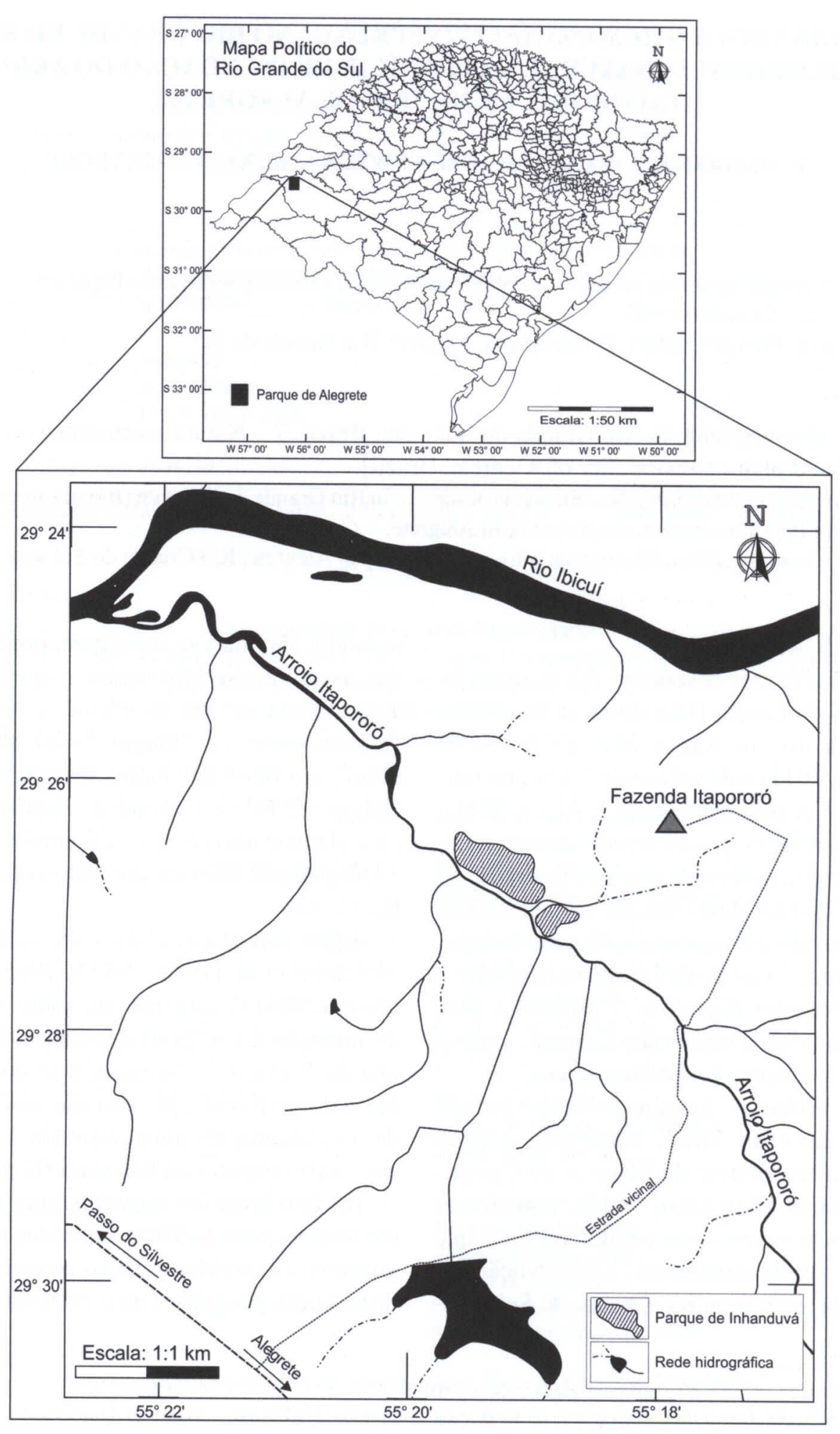

FIGURA 1 - Mapa de localização do parque de inhanduvá do Itapororó (Alegrete - RS). 
de do Sul, bem como lançar novos olhares sobre a abrangência da Província do Espinhal no Estado.

\section{DESCRIÇÃO DO PARQUE}

Posicionado, geograficamente, em torno das coordenadas de $29^{\circ} 26^{\prime} 51^{\prime \prime} \mathrm{S}$ e $56^{\circ} 19^{\prime} 14^{\prime \prime} \mathrm{O}$, o parque de inhanduvá do Itapororó se encontra a $55 \mathrm{~m}$ de altitude e ocupa parte da planície de inundação da margem direita do arroio de mesmo nome (Figura 1), distando $6 \mathrm{~km}$ à sudeste de sua foz, $43 \mathrm{~km}$ da confluência do Ibicuí no Uruguai e $133 \mathrm{~km}$ a oeste do parque de inhanduvá de Cacequi. A área em estudo pertence à Fazenda Itapororó, propriedade do Sr. Nestor de Moura Jardim Neto, e se encontra no município de Alegrete, Rio Grande do Sul.

De origem sedimentar, o terreno é formado por depósitos aluviais, com areia grossa até fina, sedimentos síltico-argilosos e diminutos fragmentos de rocha oriundos das coxilhas adjacentes, caracterizando um Planossolo Háplico Eutrófico Arênico, de acordo com Streck et al. (2008).

O clima, do tipo $\mathrm{Cfa}$, apresenta chuvas regulares em todos os meses do ano, temperatura do mês mais frio entre 3 e $18^{\circ} \mathrm{C}$, e verões com temperatura média do mês mais quente superior a $22^{\circ} \mathrm{C}$ (Moreno, 1961). De acordo com Nimer (1977), corresponde ao tipo Mesotérmico Brando Super-Úmido, sem estação seca.

A vegetação reúne algumas centenas de inhanduvás isolados (Figura 2A) ou dispostos em pequenos agrupamentos (Figura 2B), com indivíduos velhos e numerosas regenerações (Figura 2C), bem como espécies arbóreas oriundas da mata ciliar adjacente. Apesar dos impactos na fisionomia e estrutura do parque, decorrentes da intensa ação antrópica, mesmo assim não pode ser questionada a sua origem natural: tratam-se de fragmentos remanescentes de um pequeno, mas verdadeiro parque de inhanduvá, que se estende por $1100 \mathrm{~m}$ de comprimento, ao longo do arroio, com largura máxima de 400m, tendo por limite, a leste, o afloramento de solos regolíticos eutróficos, típicos do Planalto da Campanha gaúcha.

Severamente ameaçado por lavoura arrozeira, são numerosos os inhanduvás mortos em meio ao parque (Figura 3A), bem como os indivíduos com sistema radicular parcialmente exposto (Figura $3 \mathrm{C}$ ), devido à erosão causada por eventuais transbordamentos do canal principal do arroio. A abundância do capim anoni (Eragrostis plana) no estrato herbáceo é outro claro indício de antropismo. A presença de numerosos inhanduvás jovens, por sua vez, depõe favoravelmente sobre a permanência da espécie na região, à médio prazo (Figura $2 \mathrm{C}$ ).

Os troncos de velhos inhanduvás são recobertos por cactos rabo-de-rato (Lepismium lumbricoides), salientando-se, ainda, no grupo das epífitas, um cravo-do-mato (Tillandsia aeranthos) e uma pteridófita (Pleopeltis squalida). Das lianas, salientam-se o cipó-timbó (Paullinia elegans) e o maracujá-azul (Passiflora caerulea). Associado aos inhanduvás se encontram espinilhos (Vachellia caven), a unhade-gato (Senegalia bonariensis), a taleira (Celtis ehrenbergiana), o toropi (Sapium haematospermum), a coronilha (Scutia buxifolia), além de espécies lenhosas emigradas da mata ciliar adjacente, tais como: o sarandi (Terminalia australis), o branquilho (Sebastiania commersoniana), o branquilho-leiteiro (Sebastiania brasiliensis), a murta (Blepharocalyx salicifolius) e a embira (Daphnopsis racemosa).

$\mathrm{Na}$ mata ciliar, além das espécies referidas no parágrafo anterior, encontram-se, ainda: o salso-crioulo (Salix humboldtiana), o angico (Parapiptadenia rigida), o gerivá (Syagrus romanzoffiana), o açoita-cavalo (Luehea divaricata), o camboatá-vermelho (Cupania vernalis), o araçá (Myrcianthes cisplatensis), o pessegueiro-do-mato (Eugenia myrcianthes), o ariticum (Annona emarginata) e o veludinho (Guettarda uruguensis), entre outras. 

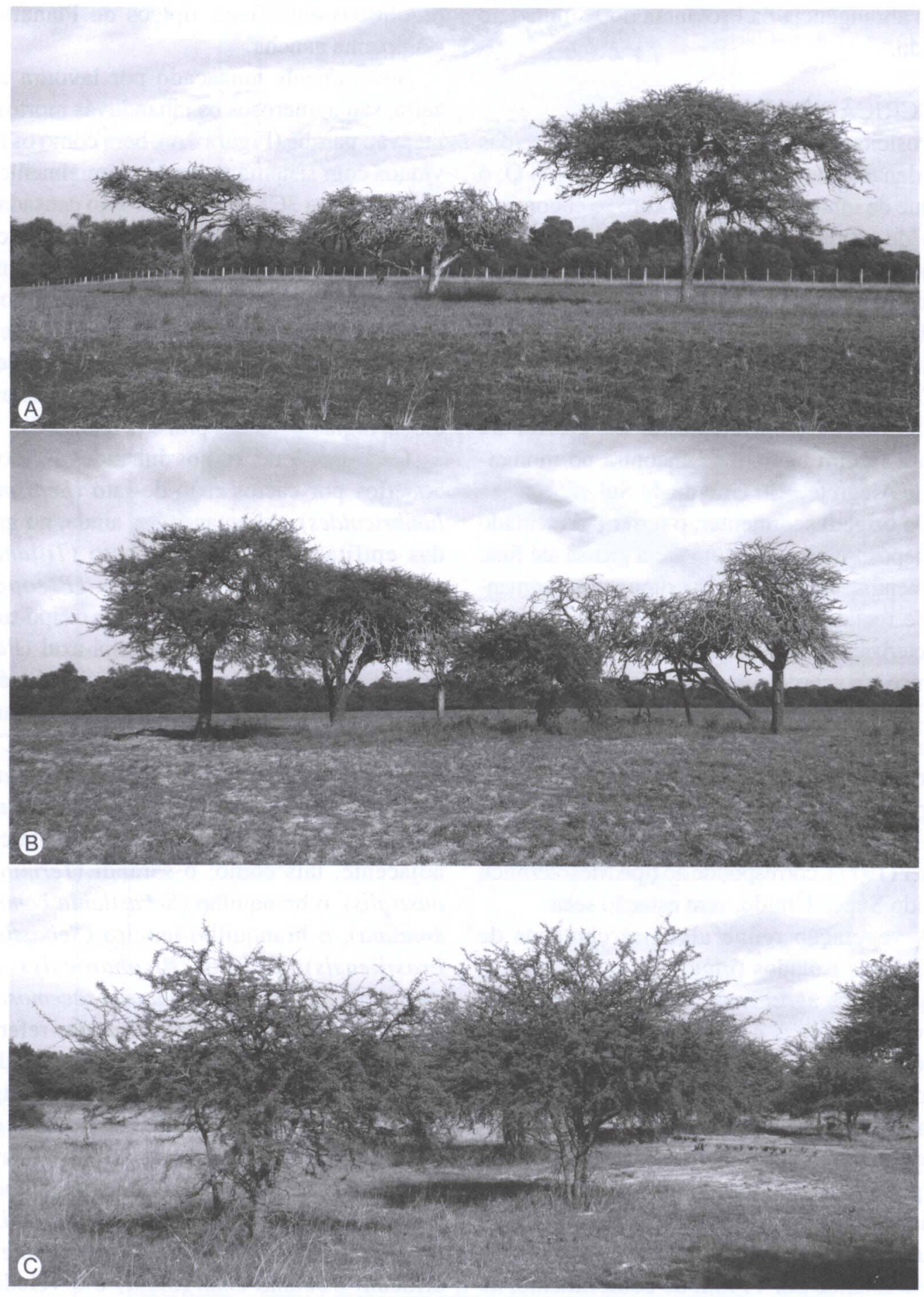

FIGURA 2 - Três aspectos da vegetação em estudo. A - Inhanduvás isolados, em área cultivada, com a mata ciliar do arroio Itapororó ao fundo. B - Agrupamento de inhanduvás, com indivíduos mortos (à direita), em meio à área cultivada. C - Indivíduos jovens de Prosopis affinis. 

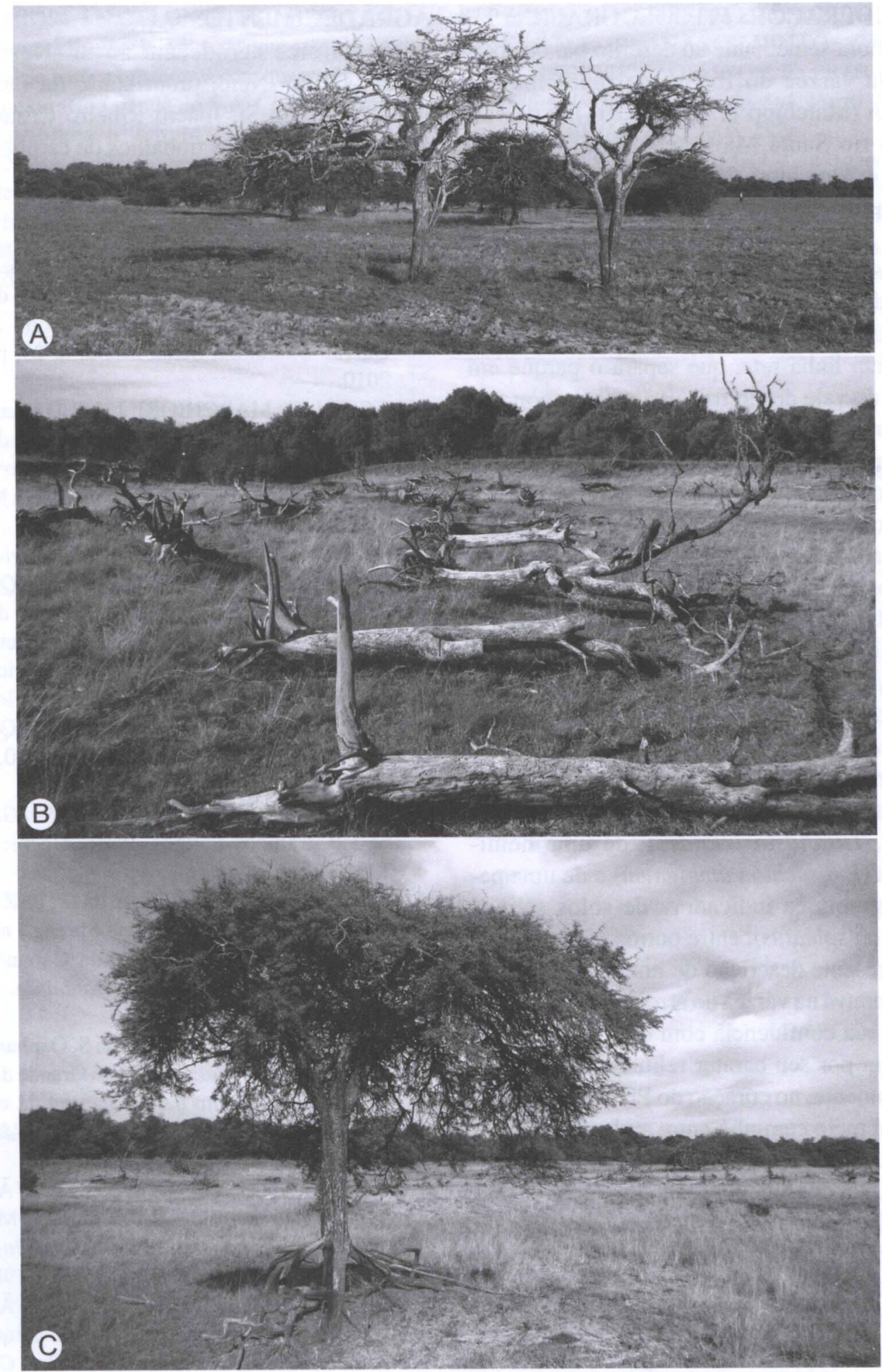

FIGURA 3 - Três imagens de degradação do parque. A - Velhos inhanduvás mortos, em primeiro plano. B - Depósito de troncos de inhanduvá. C - Velho inhanduvá com raízes parcialmente expostas, por erosão do solo. 


\section{CONSIDERAÇÕES FITOGEOGRÁFIC AS}

Embora semelhante ao descrito para os parques da várzea do Ibicuí, no município de Cacequi (Marchiori \& Alves, 2011), e da várzea do rio Santa Maria, em Rosário do Sul (Alves \& Marchiori, 2011), a vegetação presentemente descrita apresenta diversidade ainda menor no tocante ao estrato herbáceo e às sinúsias epifítica e de lianas, fato que pode ser atribuído à faixa sedimentar relativamente estreita junto ao arroio Itapororó e à distância de $6 \mathrm{~km}$, em linha reta, que separa o parque em estudo do vale do rio Ibicuí, a mais importante rota imigratória que atravessa o Planalto da Campanha.

Comparado aos parques do Pontal do Quaraí, descritos por Marchiori (2004) e Galvani \& Baptista (2003), chama atenção a ausência de diversos elementos estritamente chaquenhos, caso do algarrobo (Prosopis nigra), do quebracho-branco (Aspidosperma quebrachoblanco), da cina-cina (Parkinsonia aculeata), da sombra-de-touro (Acanthosyris spinescens), da arumbeva-de-flores-alaranjadas (Opuntia elata), da tuna (Cereus hildmannianus), de dois cravos-do-mato (Tillandsia duratii, Tillandsia ixioides), de uma hemiparasita (Eubrachion ambiguum) e de uma pequena gramínea indicadora de solos salinos (Tripogon spicatus), entre outros.

A presente descrição de um parque natural de inhanduvá na várzea do arroio Itapororó, próximo à sua confluência com o Ibicuí, tem importância por seu caráter relitual e por situarse, justamente, no coração do Planalto da Campanha, a meio caminho entre a planície aluvial do rio Uruguai e a Depressão Central. Fica reforçada, por conseguinte, a interpretação da planície sedimentar do rio Ibicuí como rota imigratória do inhanduvá, em seu pretérito avanço rumo ao interior do Rio Grande do Sul, comprovada pelos parques de Cacequi (Marchiori \& Alves, 2011), de Rosário do Sul (Alves \& Marchiori, 2011) e de São Vicente do Sul (Marchiori et al., 2010).

\section{AGRADECIMENTOS}

Os autores agradecem ao Sr. Nestor de Moura Jardim Neto, proprietário da Fazenda Itapororó, e ao Sr. Inácio Ribeiro César, que acompanhou-nos nos trabalhos de campo.

\section{REFERÊNCIAS BIBLIOGRÁFICAS}

ALVES, F. da S.; MARCHIORI, J.N.C. O inhanduvá (Prosopis affinis Spreng.) no Rio Grande do Sul. 2 - Ocorrência natural na região do Jarau, Quaraí. Balduinia, Santa Maria, n. 25, p. 1-9, 2010.

ALVES, F. da S.; MARCHIORI, J.N.C. O inhanduvá (Prosopis affinis Spreng.) no Rio Grande do Sul. 5 - Ocorrência natural na várzea do rio Santa Maria, Rosário do Sul. Balduinia, Santa Maria, n. 27, p. 1-7, 2011.

GALVANI, F.R. Vegetação e aspectos ecológicos do Parque Estadual do Espinilho, Barra do Quaraí, $R S$. Porto Alegre: Universidade Federal do Rio Grande do Sul, 2003. 132 f. Tese de Doutorado (Programa de Pós-Graduação em Botânica).

GALVANI, F.R.; BAPTISTA, L.R. de M. Flora do Parque Estadual do Espinilho - Barra do Quaraí/ RS. Revista da FZVA, Uruguaiana, v. 10, n. 1, p. 42-62, 2003.

MARCHIORI, J.N.C. Fitogeografia do Rio Grande do Sul. Campos Sulinos. Porto Alegre: EST, 2004. $110 \mathrm{p}$.

MARCHIORI, J.N.C.; ALVES, F. da S.; PAZ, E.A. O inhanduvá (Prosopis affinis Spreng.) no Rio Grande do Sul. 3 - Parque da Cabanha do Loreto, São Vicente do Sul. Balduinia, Santa Maria, n. 25, p. 22-31, 2010.

MARCHIORI, J.N.C.; ALVES, F. da S. O inhanduvá (Prosopis affinis Spreng.) no Rio Grande do Sul. 6 - Descrição de um parque natural na várzea do rio Ibicuí, município de Cacequi. Balduinia, Santa Maria, n. 27, p. 8-14, 2011.

MARCHIORI, J.N.C.; LONGHI, S.J.; GALVÃO, L. $\mathrm{O}$ gênero Prosopis L. (Leguminosae Mimosoideae) no Rio Grande do Sul. Ciência e Natura, Santa Maria, n. 5, p. 171-177, 1983.

MARCHIORI, J.N.C.; LONGHI, S.J.; GALVÃO, L. Composição florística e estrutura do parque de inhanduvá no Rio Grande do Sul. Rev. Centro de Ciências Rurais, Santa Maria, v. 15, n. 4, p. $319-334,1985 \mathrm{~A}$. 
MARCHIORI, J.N.C.; LONGHI, S.J.; GALVÃO, L. Estrutura fitossociológica de uma associação natural de parque inhanduvá com quebracho e cinacina, no Rio Grande do Sul. Ciência e Natura, Santa Maria, n. 7, p. 147-162, 1985 B.

MORENO, J.A. Clima do Rio Grande do Sul. Porto Alegre: Secretaria da Agricultura-Diretoria de Terras e Colonização, 1961. 42 p.

NIMER, R. Clima. Geografia do Brasil. Região Sul. Rio de Janeiro: IBGE, 1977. p. 35-79.
STRECK, E.V.; KÄMPF, N.; DALMOLIN, R.S.D.; KLAMT, E.; NASCIMENTO, P.C. do; SCHNEIDER, P.; GIASSON, E.; PINTO, L.F.S. Solos do Rio Grande do Sul. Porto Alegre: EMATER/ASCAR, 2008. 222p.

VELOSO, H.P.; GÓES-FILHO, L. Fitogeografia brasileira. Classificação fisionômico-ecológica da vegetação neotropical. Salvador: Projeto RADAMBRASIL, 1982. 80 p. (Boletim Técnico, Ser. Vegetação, v. 1). 